\title{
MCDM Applied to the Evaluation of Transitional and Post-Mining Conditions-An Innovative Perspective Developed through the EIT ReviRIS Project ${ }^{+}$
}

\author{
Sandra Amaro 1,*(D), Sofia Barbosa ${ }^{1}\left(\mathbb{D}\right.$, Gloria Ammerer ${ }^{2}{ }^{-}$, Aina Bruno ${ }^{3}$, Jordi Guimerà ${ }^{3}$, Ioannis Orfanoudakis ${ }^{4}$, \\ Anna Ostręga ${ }^{5}$, Evangelia Mylona ${ }^{6}$, Michael Hitch ${ }^{7}{ }^{\mathbb{C}}$ and Jessica Strydom ${ }^{8}$ \\ 1 GeoBioTec-GeoBioSciences, GeoTechnologies and GeoEngineering \& NOVA FCT, 2829-516 Caparica, \\ Portugal; svtb@fct.unl.pt \\ 2 Montanuniversität Leoben, RIC Leoben, 8700 Leoben, Austria; gloria.ammerer@unileoben.ac.at \\ 3 Amphos 21, 08019 Barcelona, Spain; aina.bruno@amphos21.com (A.B.); jordi.guimera@amphos21.com (J.G.) \\ 4 ECHMES Ltd., 4 Papadiamantopoulou, 11528 Athens, Greece; iorfanoudakis@echmes.gr \\ 5 Faculty of Civil Engineering and Resource Management, AGH University of Science and Technology, \\ 30-059 Kraków, Poland; ostrega@agh.edu.pl \\ 6 Laboratory of Metallurgy, School of Mining and Metallurgical Engineering, National Technical University of \\ Athens, 15780 Zografou, Greece; mylona@metal.ntua.gr \\ 7 WA School of Mines: Minerals, Energy and Chemical Engineering, Curtin University, Bentley, WA 6845, \\ Australia; michael.hitch@curtin.edu.au \\ 8 Department of Geology, Tallinn University of Technology—TalTech, Ehitajate tee 5, 19086 Tallinn, Estonia; \\ jessica.strydom@taltech.ee \\ * Correspondence: s.amaro@fct.unl.pt \\ check for \\ updates \\ † Presented at the RawMat2021, Athens, Greece, 5-9 September 2021.
}

Citation: Amaro, S.; Barbosa, S.; Ammerer, G.; Bruno, A.; Guimerà, J.; Orfanoudakis, I.; Ostręga, A.; Mylona, E.; Hitch, M.; Strydom, J. MCDM Applied to the Evaluation of Transitional and Post-Mining Conditions-An Innovative Perspective Developed through the EIT ReviRIS Project. Mater. Proc. 2021, 5, 22. https://doi.org/10.3390/ materproc2021005022

Academic Editor: Anthimos Xenidis

Published: 22 November 2021

Publisher's Note: MDPI stays neutral with regard to jurisdictional claims in published maps and institutional affiliations.

Copyright: (c) 2021 by the authors. Licensee MDPI, Basel, Switzerland. This article is an open access article distributed under the terms and conditions of the Creative Commons Attribution (CC BY) license (https:// creativecommons.org/licenses/by/ $4.0 /)$.

\begin{abstract}
In mine design and planning, the identification of an appropriate Post-Mining Land Use (PMLU) is necessary and crucial to achieve environmental quality, socio-economic renewal, and social acceptance of mining projects. In this context, Multi-Criteria Decision Making (MCDM) methods support decision-makers and stakeholders, identifying the relevant factors and criteria, so that, different available alternatives can be evaluated, compared, and contrasted with each other. With the vision to enable its wide application, 15 mine profiles are identified which, combined with selected MCDM methods and relevant factors, results in a Multi-Criteria Decision Analysis (MCDA) framework for PMLU. In this preliminary framework, the MCDM methods selected are SIMUS, TOPSIS, and SMARTER. They serve different problems and, therefore, are used in different profiles: SIMUS is applied to complex profiles, TOPSIS to the lesser ones, and SMARTER is used due to its capacity of assigning weights to criteria based on Ranking Order Centroid calculations. This preliminary MCDA structure gives the possibility to include the complexity (technical and decisional) and a participatory process, for all stakeholders involved concerning PMLU.
\end{abstract}

Keywords: ReviRIS; Post-Mining Land Use; MCDA; revitalisation; participatory tool; mine closure

\section{Introduction}

Post-Mining Land Use (PMLU) is a key issue regarding the public image of the mining industry. In the last century, mines were abandoned, posing environmental risks to water, soil, and air with consequent impacts on local populations and demands for Governments management. With the introduction of more restrictive environmental impact legislation, in EU countries, no mine activity presently exists without a proper closure and rehabilitation plan.

The experience gained, in more recent decades, demonstrates that it is not enough to control and reclaim environmental damages, nor to reclaim the landscape features, without considering the attribution of new functions to the site, called a revitalisation process. In 
European countries, the revitalisation of mine sites has become crucial to achieve social acceptance of mining projects. Even before and during the revitalisation process, the future land use (PMLU) needs to be studied, analysed, and selected from a set of scenarios or alternatives. For this selection, Multiple Criteria Decision Analysis (MCDA) is applied, with the aim of developing an approach that involves and integrates different, and often, conflicting criteria, to which distinct solutions exist. This approach follows a series of stages [1], namely (1) identification of the problem, (2) problem structuring, (3) model building, (4) using the model to inform and challenge thinking, and (5) developing an action plan. Each stage involves different procedures and techniques to structure the problem, as close to reality.

When a MCDA is developed to the point where what is missing is a decision it becomes a Multiple Criteria Decision-Making (MCDM) problem [1]. At this stage the problem is well structured, and criteria and alternatives are defined, however, this is not a common situation [1]. Alternatives are the solutions, projects, or scenarios under evaluation, developed to achieve the MCDA goal(s); criteria are elements, defined as small sentences and also as smaller objectives, that describe and evaluate the alternatives ([2], Ch. 2.1). Often, criteria are arranged in a hierarchy and sub-divided into attributes, generally used in the Analytic Hierarchy Process (AHP). To help decision-makers choosing one alternative, among others, there are distinct methods to apply to a MCDM problem, each of them with its advantages and disadvantages.

Some PMLU studies, such as [3-7], are MCDM problems because they start from an already structured problem and apply one method or a combination of two. In the study developed by Soltanmohammadi et al. [3-5], a framework for the suitability of the mined land to a new use is created, based on the concept developed by Knabe [8], called Mined Land Suitability Analysis (MLSA). This framework is made by 50 attributes divided into four main criteria, which are used to assess 23 specific alternatives divided into eight land uses categories. These three studies use a combination of methods: AHP is used for criteria weighting and other methods are used for alternatives' assessment (TOPSIS, ELECTRE, and PROMETHEE).

Bangian et al. [7] apply the fuzzy AHP method to a MCDM problem (problem already structured), where a link between the Optimal Post-Mining Land Use (OPMLU), of the open pit, and the Net Present Value (NPV) of the mine is made known. This link is suggested, because, considering the need of a closure planning at the feasibility and pre-feasibility stage of a mining project, the PMLU of the most affected area (usually, the open pit) will influence the NPV. In this MCDM, the problem structure comprises 17 alternatives and 96 attributes, distributed through five main criteria.

These kind of studies ([3-7]) use a large number and fixed criteria and alternatives. Their widespread application to PMLU MCDA is not certain because they require the evaluation of dozens of elements, that may not properly describe, or characterise, different mine sites. The use of AHP method allows for higher subjectivity instead of objectivity, and these studies do not include the spatial characteristics of mining activities and land use planning. Therefore, PMLU MCDA requires the development of a framework that, through a guided-though process help field experts to develop better alternatives and define criteria. At the same time, the inclusion of GIS data is crucial, so all elements are considered in a general process able to adapt to specific sites.

This study aims at the development of a general framework, used as a methodology, for post-mining planning. To achieve it, (i) Transitional Post-Mining Landscape Profiles (TPMLP) are defined to allow the decision-maker to realise the steps required for the implementation of the revitalisation process; (ii) topics are defined and applied to all post-mining decision making problems; and (iii) MCDM methods are carefully selected to analyse alternatives and define the new land uses. All these aspects are discussed and integrated in the ReviRIS decision process for PMLU. 


\section{Materials and Methods}

\subsection{Transitional Post-Mining Landscape Profiles' Definition (TPMLP)}

In the process of trying to understand how different types of mines fit in a set of categories, the following four conceptual questions are considered:

1. Is the site an active mine?

2. Does the site have a private entity responsible for the environmental liability?

3. Are field works implemented on site for environmental control and remediation?

4. Are there field works implemented for revitalisation and new land use?

The answers to these questions are "Yes", "No", "Ongoing", or "Completed" and the combinations of them lead to the definition of 15 Transitional Post-Mining Landscape Profiles. These combinations allow the grouping of the 15 profiles into three main categories, namely "abandoned mines", "not active mines", and "active mines". These categories broadly cover the legal status of mines as well as quarries. In these three definitions there are two notes: (i) the status of "abandoned" refers to old and abandoned mines, before it was mandatory by law for mining companies to environmentally reclaim the area, and (ii) not active mines refers to quarries, that are not abandoned, but instead, they are in a "stand-by" situation.

Table 1 shows the reference to the conceptual questions, the combination of answers, the main category of the site, and, in the last column, the profile's number that corresponds to each answers' combination.

Table 1. Combination of possible answers to the questions listed in the text (Q1-Q4).

\begin{tabular}{llcccc}
\hline Q1 & Q2 & Q3 & Q4 & Main Category & Profile No. \\
\hline No & No & No & No & & 1 \\
No & No & Ongoing & No & Abandoned & 2 \\
No & No & Completed & No & 3 \\
No & No & Completed & Ongoing & & 4 \\
No & No & Completed & Completed & & 5 \\
No & Yes & No & No & & 6 \\
No & Yes & Ongoing & No & Not active & 7 \\
No & Yes & Completed & No & & 8 \\
No & Yes & Completed & Ongoing & & 9 \\
No & Yes & Completed & Completed & & 10 \\
Yes & Yes & No & No & & 11 \\
Yes & Yes & Ongoing & No & Active & 12 \\
Yes & Yes & Completed & No & \\
Yes & Yes & Completed & Ongoing & & 13 \\
Yes & Yes & Completed & Completed & & 15 \\
\hline
\end{tabular}

The answer to Q1 gives the information if the site has a mine closure process or lack of it. With this, the decision process is directed to one of the following starting points of the MCDA:

1. the starting point is an area that is not expected to have other mineral exploitation, meaning that from the point of view of terrain modifications it is in a static situation,

2. the starting point is an area with active mineral exploitation, meaning that from the point of view of terrain modifications it is in a dynamic situation.

Q2 relates to the role that government or private entities play in the whole process. If the site has no private entity responsible for the environmental remediation, then that responsibility is directly attributed to the Government. This means that the Government must combine efforts to properly design, implement, and monitor the technical environmental remediation. If there is a private entity responsible for mining activity, it is the entity responsible for that effort. This question provides insight into the responsibility of the environmental liabilities' remediation, but not for the revitalisation project. 
Q3 addresses the stage of field work for environmental remediation. This information guides the decision to the level of detail for the definition of a revitalisation project. This project detail level depends on the outcome of the terrain modelling and engineering solutions to contain or treat contamination. If field work is not yet implemented, then the main decision falls on the technical and engineering solutions to be applied. However, if the field work is ongoing or completed, then revitalisation is directly considered in the decisional process, first by identifying the main theme and objectives, and then by selecting a proper revitalisation plan.

Last, Q4 reflects the attribution of managing responsibilities for the final new land use and monitoring of the environmental remediation parameters. When the process reaches a stage where the needs are related mainly with the verification of the situation of the field work implemented for the revitalisation, all decisions considering the selection of the revitalisation solutions should have been already taken, letting the decision step to be the attribution of managing responsibilities. However, the ideal process is the one where these responsibilities are accounted at the stage of selecting revitalisation project options.

\subsection{Topics' Definition}

There are studies that define criteria for PMLU, or mine reclamation in different ways depending on the approach of the study and the stakeholders involved. There are two main ways of organising criteria, (i) in a hierarchy with attributes given to sub-levels of each criterion $[4,9,10]$ or (ii) non-hierarchical [11-13] without sub-levels of criteria. The first one divides a complex problem to its main characteristics, the criteria, and enables the decision-maker to assess only one of those characteristics at each time. The second way of organising criteria enables the decision-maker to analyse the problem through a holistic lens. Aiming at a methodology to be applied, ideally, in all post-mining decision making problems, this study defines not criteria, but topics. These topics are based on criteria developed by the authors referred above, but with the novelty of the inclusion of Geoethics into the process.

Geoethics is a relatively new discipline of geosciences. It is an emerging area that deals with scientific, technological, methodological and social-cultural aspects, such as sustainability, development or even museology [14-18]. Geoethics is also concerned with the necessity of considering appropriate protocols, scientific integrity issues and developing a code of good practice, regarding the abiotic world [17] highlighting the importance of geoscientists and their work in the current civilization. One of the focus of Geoethics is related with pressing environmental subjects, those that ensure an adequate and sustainable natural resource usage, promoting suitable management of natural risks, and diffusing scientific knowledge and geoeducation [14]. All of this have social, cultural, and economic repercussions, and for that reason, Geoethics is included in decision processes, enabling the creation of solid guidelines that provide socio-economic solutions and respect the environment [14].

The reason of considering "topics" and not "criteria" is related to the objective of their creation: they are a checklist when structuring a PMLU MCDA problem to be evaluated in a decision support system. They can be further developed as criteria, constraint, restriction, or even as a theme for the design of alternatives. It will depend on the site's profile, and the goal for the MCDA. The topics are Economy, Environment, Technical issues, Social, Geoethics, and Regional Development. The latter two are new to this kind of studies. These six main topics cover all aspects related to every stage of the reclamation and revitalisation of mineral exploitation areas and are briefly described in Table 2. 
Table 2. Description of ReviRIS topics.

\begin{tabular}{|c|c|}
\hline Topic & Description \\
\hline Economics & $\begin{array}{l}\text { Costs related to the implementation of the alternative, monitoring environmental and safety } \\
\text { issues, time needed to develop such plans, the post-mining land use economic balance, and } \\
\text { the funding opportunities or possibilities. }\end{array}$ \\
\hline Environmental & $\begin{array}{l}\text { Is linked with the natural environment, such as atmospheric, aquatic, terrestrial and } \\
\text { biological domains. These domains form the baseline to develop a characterisation study of } \\
\text { the current state of the mine complex. }\end{array}$ \\
\hline Technical issues & $\begin{array}{l}\text { Intends to include into the decisional process aspects related to the mine site itself and } \\
\text { engineering. The main aspects are related to the mine physical characteristics, the measures } \\
\text { that need to be taken to cope with the type and way of contamination, the characteristics of } \\
\text { structures and facilities, the potential for circular economy, the terrain characteristics, and } \\
\text { the stability and risk conditions of the mine complex area. }\end{array}$ \\
\hline Social & $\begin{array}{l}\text { This topic relates to the economic development of local communities, future employment } \\
\text { situation, community cohesion, social structure impact, regional culture and collective } \\
\text { identity, fears and aspiration of local community, safety, health and well-being, land } \\
\text { planning, infrastructures, environment, personal and proper rights, political and } \\
\text { institutional stresses. }\end{array}$ \\
\hline Regional Development & $\begin{array}{l}\text { This is a new topic brought to the discussion of PMLU and its inclusion derives from the } \\
\text { need to add regional strategies, ambitions, and needs into the decisional process. Therefore, } \\
\text { the elements accounted are the potential for agricultural, commercial, touristic, real state or } \\
\text { other economic activities, as well as the regional strategy designed for each of those } \\
\text { activities, which is linked with the regional legislations and legal frameworks regarding } \\
\text { land management. The regional strategy for climate change adaptation also be considered, } \\
\text { as well as the distance to local communities. }\end{array}$ \\
\hline Geoethics & $\begin{array}{l}\text { This new topic intends to enable decision-makers develop a set of criteria that considers the } \\
\text { local population needs, the natural potential, the knowledge gathered through years or } \\
\text { decades of mining, the safety and health of the whole ecosystem (including humans) and } \\
\text { how it interacts with the economic activities, whether through the promotion of culture and } \\
\text { tourism or by the preservation of geological and mining heritage. }\end{array}$ \\
\hline
\end{tabular}

\subsection{Multiple Criteria Decision-Making Methods Applicable to ReviRIS Context}

In a MCDA, the methods to be used are carefully selected. There are dozens of MCDM methods ([2], Ch. 4.1.2) and each of them has its particularities. After extensive research throughout the main and most used MCDM methods, the ones selected for ReviRIS methodology are TOPSIS-Technique for Order Preference by Similarity to Ideal Solution developed by Hwang \& Yoon [19], SIMUS-Sequential Interactive Method for Urban Systems developed by Munier [20], and the weighting technique used in SMARTERSimple Multi-Attribute Rating Technique Extended to Ranking developed by Barron \& Barret [21].

In general, there are a few mathematical steps common to many MCDM methods, which corresponds to the following: (1) build the Initial Decision Matrix (IDM), that is the preparation of a matrix with data to be used in the method, where, usually, criteria are the rows and alternatives the columns of the IDM; (2) input the data in the IDM according to criteria's types of data, because distinct criteria are related with distinct unites and scales (e.g., criteria relate with monetary data, other with percentage, other with chemical concentration data, and so on); (3) incorporate criteria weights, defined by one of the many weighting methods available, if the MCDA requires it (it is not mandatory); (4) normalise the IDM, using one of the normalisation techniques, so that all criteria are within the same scale (e.g., between 0 and 1); (5) apply the mathematical procedure of the method chosen and, finally, (6) rank the alternatives according to its scores given by the method applied.

The mathematical procedure of the three different MCDM methods selected (fifth step), namely, TOPSIS, SIMUS, and SMARTER is briefly describe in the following sub-sections. 


\subsubsection{Technique for Order Preference by Similarity to Ideal Solution (TOPSIS)}

This method was introduced by Hwang \& Yoon [19], which is based on the idea that the "best" alternative is one with the shortest distance from the ideal solution and the farthest from the negative-ideal solution. When these distances are considered simultaneously in a mathematical procedure, it measures the relative closeness to the ideal solution, supporting the decision-maker regarding their choice. For this procedure, the method uses the action to input to a criterion (maximisation or minimisation), which regards to benefit and cost criteria, being benefit criteria, the ones where larger values have grater preference (tend to call for maximisation), and cost criteria, the ones where larger values have less preference (tend to call for minimisation). The specific steps of TOPSIS are the following:

Step 1: Determination of Positive-Ideal and Negative-Ideal Solutions.

To define the Positive-Ideal Solution (PIS) and the Negative-Ideal Solution (NIS), which are artificial extremes for the set of alternatives, the mathematical procedure follows the next rules:

$$
\begin{aligned}
& P I S=\left\{\left(\max _{i} v_{i j} \mid j \in J\right),\left(\min _{i} v_{i j} \mid j \in J^{\prime}\right) \mid i=1,2, \ldots, m\right\}=\left\{v_{1}^{+}, v_{2}^{+}, \ldots, v_{j}^{+}, \ldots, v_{n}^{+}\right\} \\
& N I S=\left\{\left(\min _{i} v_{i j} \mid j \in J\right),\left(\max _{i} v_{i j} \mid j \in J^{\prime}\right) \mid i=1,2, \ldots, m\right\}=\left\{v_{1}^{-}, v_{2}^{-}, \ldots, v_{j}^{-}, \ldots, v_{n}^{-}\right\}
\end{aligned}
$$

where:

$J=\{j=1,2, \ldots, n \mid j$ associated with benefit criteria $\}$,

$J^{\prime}=\{j=1,2, \ldots, n \mid j$ associated with cost criteria $\}$,

$i$ is the number of alternatives $(1,2, \ldots, m)$,

$j$ is the number of criteria $(1,2, \ldots, n)$,

$v$ is the value of $j$ th criterion on $i$ th alternative,

$v_{n}^{+}$is the value of the $n$th criterion of the PIS alternative,

$v_{n}^{-}$is the value of the $n$th criterion of the NIS alternative.

These rules ensure that the artificial positive extreme solution (PIS) refers to the most preferable alternative and that the artificial negative extreme solution (NIS) refers to the least preferable alternative.

Step 2: Calculation of the separation measure.

After step 1, TOPSIS method requires the calculation of the distance between the alternatives to be considered and PIS and NIS artificial alternatives. This step is to "calculate the separation measure" [19] between each alternative and PIS, and at a second step, between each alternative and NIS, and it uses the Euclidean distances between performance values of the considered alternatives. The equations are as follows:

- "Positive" distances, between each alternative to PIS alternative

$$
D_{i}^{P I S}=\sqrt{\sum_{j=1}^{n}\left(v_{i j}-v_{j}^{+}\right)^{2}}
$$

- "Negative" distances, between each alternative to NIS alternative

$$
D_{i}^{N I S}=\sqrt{\sum_{j=1}^{n}\left(v_{i j}-v_{j}^{-}\right)^{2}}
$$

Step 3: Calculation of the relative closeness to the ideal solution.

The final specific step of TOPSIS is the calculation of the relative distance of each alternative to the artificial ones to find the alternative that is closest to PIS and farthest to NIS, using the next equation:

$$
S_{A_{i}}=\frac{D_{i}^{N I S}}{D_{i}^{\text {PIS }}+D_{i}^{N I S}}, 0<S_{A_{i}}<1
$$


where $S_{A_{i}}$ represents the relative distance of alternative $A_{i}$ to PIS and NIS, which falls between 0 and 1 . The closer the value is to 1 , the closer the alternative is to PIS. This value provides good insight to the decision-maker about the alternative to choose.

\subsubsection{Sequential Interactive Method for Urban Systems (SIMUS)}

SIMUS was developed by Munier in his $\mathrm{PhD}$ thesis [20] and further described in Munier [22] and Munier et al. [2]. This method models MCDA problems where multiple objectives need to be met, dependent criteria are in place, alternatives, or projects require precedence by other alternatives, and it does not impose limits to the number of criteria or alternatives used. They can be as many as needed and because all of this, SIMUS can be applied to complex scenarios regarding any issue. Examples are prioritisation of local viable renewable energy sources, urban transport selection, groundwater pumping for irrigation purposes, road projects, and railways planning [23-27].

In order to deal with complex decision problems, SIMUS is a hybrid method that combines Linear Programming (LP), with heuristic methods, namely, weighted sum, and outranking procedures ([2], Ch. 7), [25]. It is run in two main stages. The first stage is the application of the Simplex Linear Programming Algorithm that enables the method to find optimal solutions, if they exist, for each criterion that is used as an objective function of the LP. This process generates a Pareto Efficient Matrix that holds all the optimal values for the objective functions (criteria used as such). Based on these optimal results, a weighted sum technique is applied to alternatives which output is the first ranking of the alternatives. After the first ranking result, the method applies the outranking technique for the examination of the dominant alternative on criteria and the calculation of the difference between the dominant and subordinated alternatives, giving the second ranking solution.

\subsubsection{Simple Multi-Attribute Rating Technique Extended to Ranking (SMARTER)}

The reason to use this method in ReviRIS is because it allows to include the preferences of stakeholder's regarding the importance of criteria and therefore it is suitable for the participatory stage. This method can be applied through a questionnaire, designed specifically for the site and problem under appraisal, the answers aggregated to give weights to criteria and then used in TOPSIS or SIMUS. The studies of Pontiglioni, I. [28] and Assuma et al. [29] used SMARTER for this purpose: to rank criteria according to the preferences of different stakeholders.

Although SMARTER is a MCDM method, the technique that it uses to determine weights, the Rank Order Centroid (ROC) weights [21], is well fitted in the purpose of weighting criteria. This requires an adaptation of the SMARTER procedure, not to help in the decision regarding which is the best alternative, but to help in the reasoning of the collective preference of criteria to address the decision problem under evaluation.

The calculation of ROC weights follows the next equation.

$$
w_{k}=\frac{1}{K} \sum_{i=k}^{K} \frac{1}{i}
$$

where:

$k$ is the ranked position of each criterion

$w_{k}$ is the calculated weight (ROC weight),

$K$ is the total number of criteria, or attributes, that are to be ranked.

The constrain of this method is that it does not allow more than 16 criteria, because from that value on, the ROC weight attributed to each criterion is too small and the difference of importance between criteria starts to become irrelevant.

As referred, in ReviRIS methodology, this method is applied at a participatory stage, when all alternatives, criteria, and data for the IDM are clearly defined. Therefore, the 
questionnaire focuses on the stakeholders' preferences about the ranking of criteria under each topic. The results are the weights to be used on TOPSIS or SIMUS.

\section{Results and Discussion: ReviRIS Decision Process for PMLU}

The definition of TPMLP allows the decision-maker to structure the MCDA for a specific mine site, but also to be guided through the steps needed to complete the revitalisation process, which are (1) environmental reclamation with engineering solutions selected, (2) revitalisation stage with the theme and selection of the specific new land use, and finally (3) the attribution of responsibilities over monitoring of the environmental reclamation works and over the managing site's responsibility. These steps are granted by the formulation of four conceptual questions and their answers, which provide the following reasoning regarding the MCDA problem:

- Questions 1 and 2 helps in defining the situation of the site (static/dynamic or abandoned/inactive/active), and who take the responsibility to develop the process of mine reclamation which, in turn, reveals a significant part: the main stakeholders involved. This does not mean that all other types of possible stakeholders be disregarded, but instead means that those main stakeholders are the ones going forward with the process.

- Question 3 provides insight regarding the stage of completion of terrain modelling and implementation of engineering solutions which, in turn, allows for the level of detail for the revitalisation project,

- Question 4 indicates that the process is at the final stage. The main reason to use this methodology, at this stage, it to determine the entity(ies) that will be the final manager(s) for the monitoring of the environmental reclamation works and the manager(s) for the new specific land use.

Considering the reasoning that these questions provide regarding the problem, $\mathrm{Re}-$ viRIS project develops a methodology divided in three stages (Figure 1):

First stage-TPMLP definition and selection through the four conceptual questions already referred,

Second stage-development of alternatives, definition of criteria based on topics, creation of spatial and non-spatial data, by a group of experts, to input into the IDM, and test of the model using the suitable method (TOPSIS or SIMUS); and

Third stage-participatory process with all stakeholders involved where the alternatives and criteria are explained, and stakeholders, not only attribute their preferences regarding criteria using SMARTER, but are also involved in the decision process, observing the modeling result with TOPSIS or SIMUS, and collaborating in its sensitivity analysis.
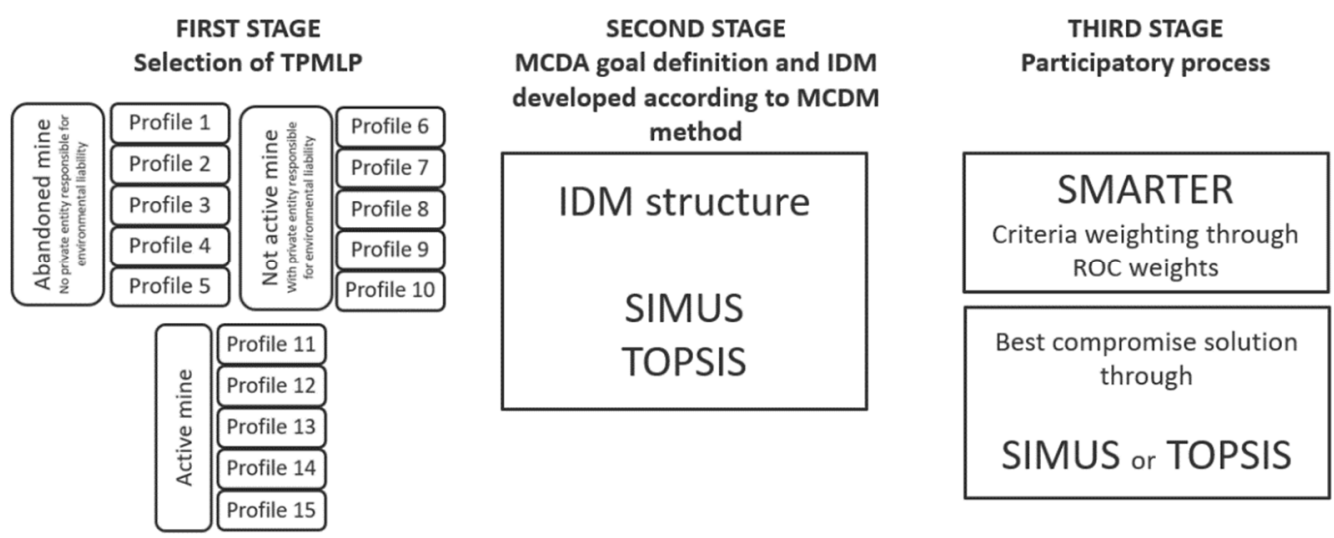

Figure 1. ReviRIS methodology's steps for the MCDA regarding PMLU decision. The first stage regards the selection of the TPMLP; the second stage corresponds to development of criteria and alternatives to build the Initial Decision Matrix (IDM); and the third stage regards the participatory process with all stakeholders. 
With this structure, TPMLP are grouped regarding their MCDA goal (Table 3), which is directly linked with the answers to the questions Q1, Q2, Q3, and Q4, and reflect the steps still needed to complete the revitalisation process. Table 3 represents the relationship between the answers (through their TPMLP), the MCDA goal, and the suitable methods to be used.

Table 3. Relationship proposed between profiles, MCDA goal, and methods, and general framework of ReviRIS MCDA tool.

\begin{tabular}{|c|c|c|c|}
\hline Profiles No. & MCDA Goals & Methods & Participatory Stage \\
\hline 1,6 , and 11 & $\begin{array}{l}\text { Analyse the technical } \\
\text { solutions to be implemented } \\
\text { in the field. }\end{array}$ & SIMUS & $\begin{array}{l}\text { SMARTER for criteria's } \\
\text { weights definitionSIMUS to } \\
\text { run the complete IDM }\end{array}$ \\
\hline 2,7, and 12 & $\begin{array}{c}\text { Define a general objective of } \\
\text { the future possible land use } \\
\text { (ex.: agriculture, natural, real } \\
\text { state ... ). }\end{array}$ & TOPSIS & $\begin{array}{l}\text { SMARTER for criteria's } \\
\text { weights definitionTOPSIS to } \\
\text { run the complete IDM }\end{array}$ \\
\hline 3,8, and 13 & $\begin{array}{l}\text { Select the specific future } \\
\text { PMLU } \\
\text { (ex.: museum, hotel, resort, } \\
\text { wheat plantations, corn } \\
\text { plantations ... ) }\end{array}$ & SIMUS & $\begin{array}{l}\text { SMARTER for criteria's } \\
\text { weights definitionSIMUS to } \\
\text { run the complete IDM }\end{array}$ \\
\hline 4,9, and 14 & $\begin{array}{l}\text { Final responsibilities: } \\
\text { (1) monitoring of } \\
\text { environmental reclamation; (2) } \\
\text { managing of the new land use }\end{array}$ & TOPSIS & $\begin{array}{l}\text { SMARTER for criteria's } \\
\text { weights definitionTOPSIS to } \\
\text { run the complete IDM }\end{array}$ \\
\hline 5,10, and 15 & No need to develop a MCDA & $\longrightarrow$ & $\longrightarrow$ \\
\hline
\end{tabular}

Profiles 1, 6, and 11 correspond to mines without environmental reclamation field work, so, their MCDA goal is the engineering solution, ideally with an eye on the revitalisation theme. For this, SIMUS is better than TOPSIS due to the higher level of complexity that it can handle.

For profiles 2,7 , and 12 , the goal is to find a revitalisation theme that enables a definition of specific new land uses after the environmental reclamation field work is completed. At this stage, the level of complexity is not as high as in previous profile group and therefore TOPSIS is suitable.

Regarding profiles 3,8, and 13, they correspond to the stage after profiles 2, 7, and 12 , which means that the MCDA goal is to select the specific new land use, but also considering the future manager (for environmental monitoring control and new land use). This represents a new complex problem and therefore SIMUS is to be used.

Profiles 4, 9, and 14 are the last group that has MCDA goal, and it is related to the management responsibility, either for environmental reclamation or for the new land use. Once this is a simple problem, TOPSIS is suitable. Lastly, profiles 5, 10, and 15 do not need to have a MCDA goal because they already have all field work completed, however, it is possible that they may not have yet managing responsibilities attributed and, in that case, they are considered as profiles 4, 9, or 14 .

A full workflow for ReviRIS decision process is proposed in Figure 2 which links the TPMLP, MCDA goals, and stages of the methodology presented previously, with GIS data integration and stakeholders' involvement. This figure summarises the whole decision process into the following stages:

1. The first stage is the selection of the TPMLP, which consists of a simple description of the site using the four simple questions, that allows to know the stakeholders involved and their responsibilities. With this first step, the MCDA goal is better understood and is possible to start the development of alternatives. 
2. For the second stage, design the alternatives, a careful analysis regarding site's intrinsic characteristics (local conditions), restrictions to future new land uses, integration with local, regional, and national spatial and non-spatial data is needed. This analysis with GIS data integration will provide the experts the information needed to develop grounded and meaningful alternatives, determining the set of criteria that better represents the problem, based on the topics, and attribute the correct performance values (data) into de IDM. After this problem structuring (MCDA stage), the situation has evolved to a stage of MCDM, where a decision is needed.

3. The final stage is the participatory process that takes place involving all stakeholders and allowing them to include their preferences, by attributing weights to criteria, using SMARTER method. In the end, and after a sensitivity analysis, which is the stage where parameters are subject to changes to model different scenarios and understand the robustness of the results, all stakeholders and decision-makers are better prepared to make a decision.

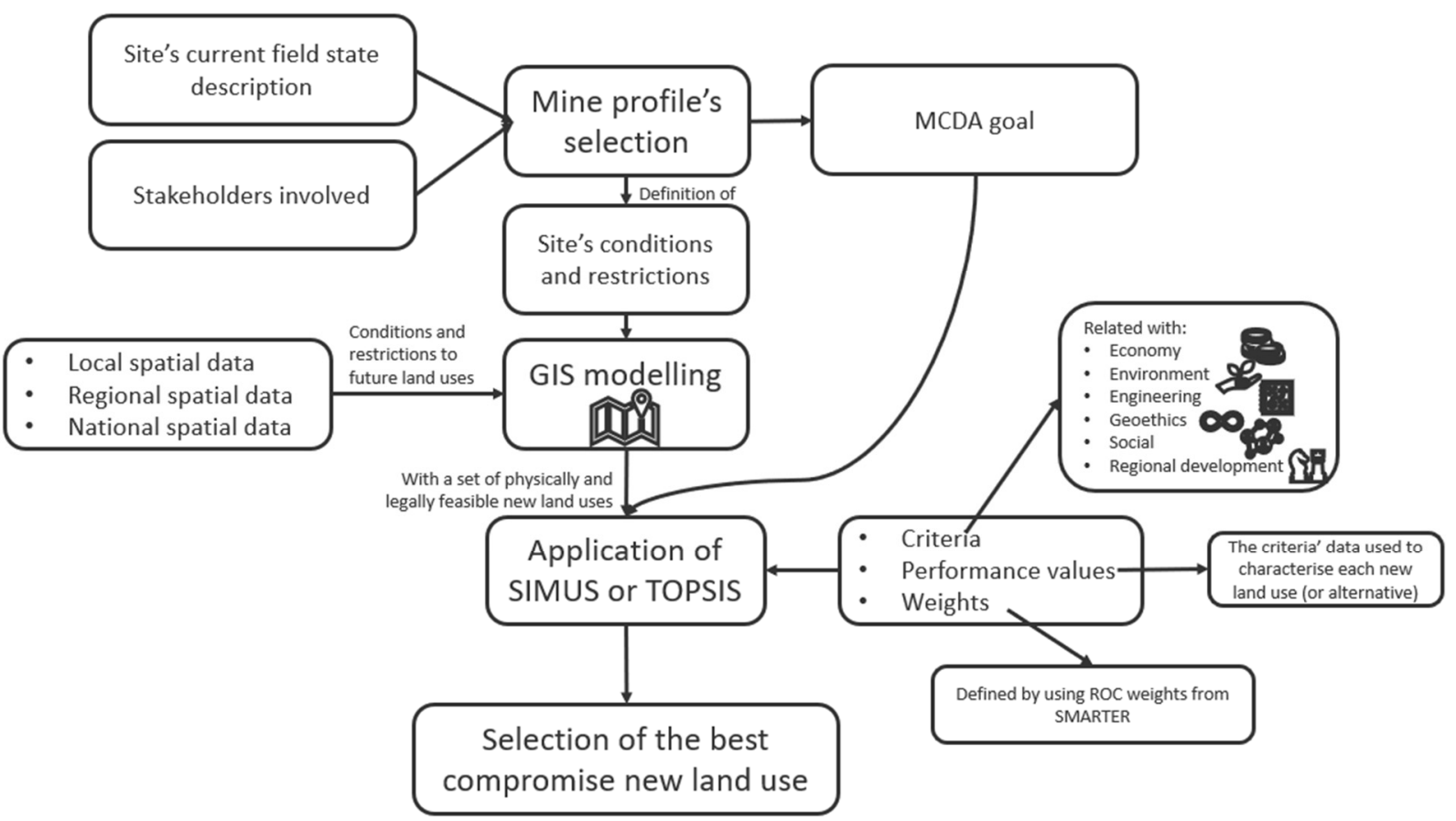

Figure 2. Representation of the overall ReviRIS methodology through a possible workflow. This workflow starts by the selection of the TPMLP (mine's profile) which implies the site's description and understanding which the stakeholders are involved; the definition of alternatives and criteria, based on topics, using different types of data (spatial and non-spatial); the application of SIMUS or TOPSIS to assess the alternatives with criteria's weights derived from SMARTER. At the end, a decision needs to be made to select the best compromise solution for the new land use.

\section{Conclusions}

In this study, the authors present the basis for a methodology for post-mining planning, on which the mining area profiles correspond to the legal state of the mine and allows for a logical and sequential process concerning the MCDA goals. Known and new topics and criteria covering all aspects related to every stage of the environmental reclamation and revitalisation of mineral exploitation areas are included in the decision process. Consequently, the methodology leads to the development of better and grounded alternatives, which helps decision-making in post-mining land use planning. The modelling approach was also developed under the objective of including results that can be derived from public participatory processes. Further work involves methodology and model verification using case studies of different TPMLP. 
Author Contributions: Conceptualization, S.B. and S.A.; writing-original draft preparation, S.A. and S.B.; writing—review and editing, S.A, S.B., G.A., I.O., A.O., E.M., M.H., J.S.; supervision, S.B.; project administration, M.H., J.S.; funding acquisition, M.H., J.S.; project dissemination: A.B., J.G. All authors have read and agreed to the published version of the manuscript.

Funding: This work was co-funded by 1) EIT Raw Materials, under grant agreement 19075: ReviRISRevitalising Post-Mining Regions, and 2) FCT-Fundação para a Ciência e a Tecnologia, Portugal under project $\mathrm{nr}$ UIDB/04035/2020.

Institutional Review Board Statement: Not applicable.

Informed Consent Statement: Not applicable.

Data Availability Statement: Data available in a publicly accessible repository that does not issue DOIs. Publicly available datasets were analyzed in this study. This data can be found here https: / / taltech.ee/en/post-mining-regions\#p47091 (accessed: 16 November 2021).

Conflicts of Interest: The authors declare no conflict of interest. The funders had no role in the design of the study; in the collection, analyses, or interpretation of data; in the writing of the manuscript, or in the decision to publish the results.

\section{References}

1. Belton, V.; Stewart, T.J. Introduction. In Multiple Criteria Decision Analysis; Springer: Boston, MA, USA, $2002 ;$ pp. 1-12.

2. Munier, N.; Hontoria, E.; Jiménez-Sáez, F. Strategic Approach in Multi-Criteria Decision Making; Springer International Publishing: Cham, Switzerland, 2019; Volume 275.

3. Soltanmohammadi, H.; Osanloo, M.; Bazzazi, A.A. Deriving preference order of post-mining land-uses through MLSA framework: Application of an outranking technique. Environ. Geol. 2009, 58, 877-888. [CrossRef]

4. Soltanmohammadi, H.; Osanloo, M.; Aghajani Bazzazi, A. An analytical approach with a reliable logic and a ranking policy for post-mining land-use determination. Land Use Policy 2010, 27, 364-372. [CrossRef]

5. Soltanmohammadi, H.; Osanloo, M.; Rezaei, B.; Aghajani Bazzazi, A. Achieving to some outranking relationships between post mining land uses through mined land suitability analysis. Int. J. Environ. Sci. Technol. 2008, 5, 535-546. [CrossRef]

6. Bangian, A.H.; Ataei, M.; Sayadi, A.; Gholinejad, A. Optimizing post-mining land use for pit area in open-pit mining using fuzzy decision making method. Int. J. Environ. Sci. Technol. 2012, 9, 613-628. [CrossRef]

7. Bangian, A.H.; Ataei, M.; Sayadi, A.; Gholinejad, A. The application of fuzzy madm modeling to define optimum post mining land use for pit area to recognize reclamation costs in open pit mining. Arch. Min. Sci. 2011, 56, 93-118.

8. Knabe, W. Methods and Results of Strip-Mine Reclamation in Germany. Ohio J. Sci. 1964, 64, 75-105.

9. Bottero, M.; Ferretti, V.; Pomarico, S. Assessing Different Possibilities for the Reuse of an Open-pit Quarry Using the Choquet Integral. J. Multi-Criteria Decis. Anal. 2014, 21, 25-41. [CrossRef]

10. Spanidis, P.-M.; Roumpos, C.; Pavloudakis, F. A Multi-Criteria Approach for the Evaluation of Low Risk Restoration Projects in Continuous Surface Lignite Mine. Energies 2020, 13, 2179. [CrossRef]

11. Bottero, M.; Ferretti, V.; Figueira, J.R.; Greco, S.; Roy, B. Dealing with a multiple criteria environmental problem with interaction effects between criteria through an extension of the Electre III method. Eur. J. Oper. Res. 2015, 245, 837-850. [CrossRef]

12. Pavloudakis, F.; Galetakis, M.; Roumpos, C. A spatial decision support system for the optimal environmental reclamation of open-pit coal mines in Greece. Int. J. Mining, Reclam. Environ. 2009, 23, 291-303. [CrossRef]

13. Palogos, I.; Galetakis, M.; Roumpos, C.; Pavloudakis, F. Selection of optimal land uses for the reclamation of surface mines by using evolutionary algorithms. Int. J. Min. Sci. Technol. 2017, 27, 491-498. [CrossRef]

14. Wyss, M.; Peppoloni, S. Geoethics: Ethical Challenges and Case Studies in Earth Sciences, 1st ed.; Elsevier: Amsterdam, The Netherlands, 2015.

15. Nikitina, N. GEOETHICS: Theory, Principles, Problems, 2nd ed.; Geoinformmark, Ltd.: Moscow, Russia, 2016.

16. Bobrowsky, P.; Cronin, V.S.; Di Capua, G.; Kieffer, S.W.; Peppoloni, S. The Emerging Field of Neuroepigenetics. In Scientific Integrity and Ethics in the Geosciences, 1st ed.; Gundersen, L.C., Ed.; American Geophysical Union (AGU): Washington, DC, USA; John Wiley and Sons, Inc.: Hoboken, NJ, USA, 2017; pp. 175-212.

17. Acevedo, R.D.; Frías, J.M. Geoethics in Latin America, 1st ed.; Springer International Publishing: Cham, Switzerland, 2018.

18. Poch, J. Geoethics: Basic Concepts and Its Potential for UNESCO Geoparks. In Geoethics in Latin America, 1st ed.; Acevedo, R.D., Frías, J.M., Eds.; Springer International Publishing: Cham, Switzerland, 2018; pp. 7-20.

19. Hwang, C.-L.; Yoon, K. Methods for Multiple Attribute Decision Making. In Lecture Notes in Economics and Mathematical Systems; Bechmann, M., Kunzi, H.P., Eds.; Springer: Berlin/Heidelberg, Germany, 1981; pp. 58-191.

20. Munier, N. Procedimiento Fundamentado en la Programación Lineal para la Selección de Alternativas en Proyectos de Naturaleza Compleja y con Objetivos Múltiples. Ph.D. Thesis, Universitat Politècnica de València, Valencia, Spain, 2011.

21. Barron, F.H.; Barrett, B.E. The efficacy of SMARTER-Simple Multi-Attribute Rating Technique Extended to Ranking. Acta Psychol. 1996, 93, 23-36. [CrossRef] 
22. Munier, N. A Strategy for Using Multicriteria Analysis in Decision-Making; Springer: Dordrecht, The Netherlands, 2011.

23. Nigim, K.; Munier, N.; Green, J. Pre-feasibility MCDM tools to aid communities in prioritizing local viable renewable energy sources. Renew. Energy 2004, 29, 1775-1791. [CrossRef]

24. Stoilova, S.D. A multi-criteria approach for evaluating the urban transport technologies by using SIMUS method. IOP Conf. Ser. Mater. Sci. Eng. 2019, 618, 012059. [CrossRef]

25. Garcia-Cascales, M.S.; Molina-Garcia, A.; Sanchez-Lozano, J.M.; Rubio-Aliaga, A.; Munier, N. Assessment of Groundwater Pumping Alternatives for Irrigation Purposes based on the SIMUS Method. In Proceedings of the 2020 IEEE International Conference on Environment and Electrical Engineering and 2020 IEEE Industrial and Commercial Power Systems Europe (EEEIC/I\&CPS Europe), Madrid, Spain, 9-12 June 2020; pp. 1-6. [CrossRef]

26. Stoilova, S.; Munier, N.; Kendra, M.; Skrúcaný, T. Multi-Criteria Evaluation of Railway Network Performance in Countries of the TEN-T Orient-East Med Corridor. Sustainability 2020, 12, 1482. [CrossRef]

27. Stoilova, S.; Munier, N. A Novel Fuzzy SIMUS Multicriteria Decision-Making Method. An Application in Railway Passenger Transport Planning. Symmetry 2021, 13, 483. [CrossRef]

28. Pontiglione, I. Valutazione Economica Spazializzata del Paesaggio del Roero. Strumento per la gestione di scenari di sviluppo territoriale. Master's Thesis, Politecnico di Torino, Turin, Italy, 2018. Available online: https://webthesis.biblio.polito.it/7778/ (accessed on 11 January 2021).

29. Assumma, V.; Bottero, M.; Pontiglione, I. A Spatial Multicriteria Analysis for Exploring Territorial Scenarios of Economic Attractiveness. In Proceedings of the Energy for Sustainability International Conference 2019, Designing a Sustainable Future, Turin, Italy, 24-26 July 2019. 